Please cite as: Jaspal, R. (2020). Honour beliefs and identity among British South Asian gay men. In M. Idriss (eds.), Men, Masculinities and Honour-Based Abuse. London: Routledge.

\title{
Honour beliefs and identity among British South Asian gay men
}

\author{
Rusi Jaspal \\ De Montfort University, Leicester, UK \\ rusi.jaspal@cantab.net
}

\section{Introduction}

Lesbian, gay, bisexual and transgender (LGBT) communities in the United Kingdom have made significant strides in gaining equality over the last fifty years. Homophobia appears to be decreasing in British society. Many now feel able to disclose their identities to others. LGBT people are now able, and many choose, to get married and to become parents. Yet, the experience of ethnic and religious minority individuals who identify as LGBT does not fit comfortably within this narrative of equality. Many experience difficulties in reconciling their ethnicity, religion and sexuality, in obtaining parental acceptance of their sexual identity, and in coming out to significant others. They may face significant social and psychological stressors, such as rejection and discrimination, that adversely impact their identity, wellbeing and relationships (Jaspal, Lopes \& Rehman, 2019).

In some collectivist cultures, there are coercive beliefs regarding 'honour', its role in the family's continuity and wellbeing, and the way in which it should be assessed, regulated and safeguarded (Soni, 2013). In these cultures, homosexuality may be regarded as a threat to honour and, thus, rejected as a cultural anomaly. LGBT people from collectivist cultural groups with strong honour beliefs may experience threats to their identity and negative emotional experiences and, consequently, feel unable to disclose their sexual identity to others. Some are clearly at risk of honour-based violence and forced marriage. As a case study, this chapter focuses on honour beliefs in the British South Asian community and the impact for identity and wellbeing among British South Asian gay men. Through the lenses of social representations theory and identity process theory from social psychology, this chapter focuses on the social psychological underpinnings of parental reactions to coming out, which may culminate in honour abuse and forced marriage, and identity and experience among British South Asian who come out as gay.

\section{Family honour: social representation and identity}

Honour is a difficult construct to define. It means different things to different groups and individuals. It is not easily delineable from other constructs, such as tradition and culture. However, there do appear to be some characteristics of honour that are shared across cultures. Vandello and Cohen (2003, p. 997) aptly define honour as 'virtuous behavior, good moral character, integrity, and altruism' and note that 'this ideal holds for males as well as females'. Their definition suggests that honour concerns cognition, affect and behaviour, and that it is more likely to be valued in collectivist, than in individualist, societies.

In South Asian communities, the Urdu term 'izzat' is used to capture the concept of honour - Gill and Brah (2014, p. 73-74) define 'izzat' as having 'multiple connotations and overlapping meanings related to respect, esteem, dignity, reputation and virtue' which is dependent on 'a wide spectrum of sociocultural relationships and ties that bind family and community groups together.' The antonym of izzat is 'sharam' which is the Urdu term for 'shame' - this amounts to a social or behavioural transgression which, in one way or another, undermines family honour. Although in South Asian communities, women are viewed as 
being central to family honour and their behaviour is particularly scrutinised (Gill, 2011), the conduct of men can also enhance or undermine family honour. As highlighted later in this chapter, religion, ethnicity, and caste are of varying importance to South Asian communities and the norms, values and expectations associated with some or all of these identities can be integral to maintaining izzat. For instance, it is possible that, by marrying someone of another caste group or by leaving the Islamic faith, one would be accused of bringing 'sharam' on the family (e.g. Jaspal, 2011a).

Honour beliefs clearly possess a psychological dimension in addition to its cultural underpinnings. Why do people hold such beliefs? What social and psychological functions do they perform? What can happen if 'honour' is perceived to be violated? Both social representations theory (Moscovici, 1988) and identity process theory (Jaspal \& Breakwell, 2014) can shed light on the social psychological underpinnings of honour and its significance for British South Asians.

\section{Social representations theory}

Social representations theory (Moscovici, 1988) provides a useful framework for exploring how members of any given group or community develop an understanding of, and are able to communicate about, their cultures and identities. Moreover, the theory provides insight into the broader social, political and ideological contexts in which people construct their identities, develop individual attitudes and relate to others. The theory can enable us to understand the development and maintenance of honour beliefs and how they relate to the issue of homosexuality, for instance. Social representations theory was originally designed to examine how esoteric topics become 'common sense' knowledge over time, that is, how they enter public consciousness and become topics that can be discussed.

At a basic level, a social representation can be defined as a collective 'elaboration' of a given phenomenon (such as honour) which in turn enables individuals to think and talk about it. This elaboration consists of emerging beliefs, values, ideas, images and metaphors in relation to a phenomenon. Social representations provide a cultural group with a shared social reality or 'common consciousness'. Family honour can be considered a social representation - it facilitates particular ways of thinking, talking and behaving and inhibits others. For instance, the social representation of family honour dictates compulsory heterosexuality in male family members and constructs homosexuality as a violation of family honour and, in some cultures, as a religious sin (Yip \& Khalid, 2010).

Two principal social psychological processes converge in the creation of social representations:

- anchoring refers to the process whereby a novel, unfamiliar phenomenon is integrated into existing ways of thinking. For instance, in South Asian cultures, family honour is often linked to the 'essence' of the family, that is, the long-standing norms, values and traditions of the family. This means that a violation of family honour essentially amounts to a 'stain' on the family's reputation and implies that the norms, values and traditions of the family are inferior to those of other families in the cultural ingroup. Individuals may, thus, come to believe that moral and social transgressions are 'typical' in that family and, thus, generalise the actions of one family member to the entire family unit. In view of this example of anchoring, it is easy to see why families may fear, and thus attempt to curb or conceal, the moral and social transgressions of a family member.

- objectification refers to the process whereby an abstract phenomenon is rendered concrete and tangible, often through the use of metaphors and personification. For instance, although the conduct of both males and females in the family can impact family honour, family honour is often personified in terms of female family members 
(and especially daughters) (Gill, 2011). Thus, they are often viewed a 'symbol' of family honour. Even in penalising homosexuality among male family members, British South Asian parents may point to the adverse effect that knowledge of their homosexuality could have for the marital prospects of daughters - the symbol of family honour (Jaspal, 2019).

Anchoring and objectification occur in a wide range of contexts, including the media, film and literature, political discourse, and in everyday conversation. Interactions in these contexts all contribute to the genesis and development of social representations. Although introduced in one context (e.g. the print media), the representation may subsequently be taken up, elaborated or challenged in other contexts (e.g. a conversation in the local pub). In short, they emerge and develop as a result of social interactions between people (Jaspal, Nerlich \& Cinnirella, 2014).

\section{Identity process theory}

Identity process theory is an integrative social psychological theory of identity construction, threat and coping. Identity process theory can enable us to understand both the psychological significance of family honour and the challenges individuals face in constructing, protecting and reconciling a gay identity. According to the theory, identity is constructed through two universal processes: assimilation-accommodation and evaluation.

- The assimilation-accommodation process refers to the absorption of new information in the identity structure (e.g. 'my son is gay') and of the adjustment which takes places in order for it to become part of the structure (e.g. 'my son is gay so my family's relationship with our cultural community may need to change').

- The evaluation process confers meaning and value upon the contents of identity (e.g. 'being gay is negative and sinful'). Family honour may be utilised as a 'lens' for evaluating homosexuality. In short, homosexuality may be constructed in negative terms because it is perceived as a threat to family honour.

These processes are guided by identity principles, which 'specify the end states that are desirable for identity' (Breakwell, 1986, p. 24). There are at least five identity principles.

- Self-esteem refers to personal and social worth.

- Self-efficacy can be defined as the belief in one's competence and control.

- Distinctiveness refers to feelings of uniqueness and differentiation from others.

- Continuity is essentially the psychological thread between past, present and future.

- Coherence refers to the perception that relevant aspects of identity are coherent and compatible.

When the identity principles are abrogated as a result of changes in one's social context (e.g. coming out as gay), identity is threatened, which is aversive for psychological wellbeing. For instance, the perception that one's sexual orientation is inconsistent with one's religious identity could plausibly challenge the coherence principle of identity, while the representation of homosexuality as a religious sin might challenge the self-esteem principle. Conversely, maintaining family honour potentially enables the individual to derive a sense of continuity since it facilitates a positive sense of lineage between past and present generations.

In response to identity threat, the individual will attempt to deploy strategies for coping with, or for reducing the negative impact of, the threat. A coping strategy is defined as 'any activity, in thought or deed, which has as its goal the removal or modification of a threat to identity' (Breakwell 1986, p. 78). Coping strategies can function at intrapsychic, interpersonal and/ or intergroup levels. For instance, it may be possible to deny the source or implications of a threat, such as one's sexual orientation (intrapsychic); to isolate oneself from individuals who denigrate one's sexual orientation (interpersonal); or to engage with 
like-minded others to form a group membership on the basis of a stigmatised identity element, such as one's sexual orientation (intergroup).

Although coping strategies are designed to reduce, assuage or eliminate the threat to identity, they vary in their level of effectiveness - some have only short-term benefits while others may be difficult to implement in the short term but are successful over time. In the remainder of this chapter, tenets of both social representations theory and identity process theory are invoked to illustrate the significance of honour beliefs in the lives of British South Asian gay men.

\section{British South Asian communities}

The category 'British South Asian' is used to refer to UK residents of South Asian ancestry, including those of Indian, Pakistani, Bangladeshi, Sri Lankan and Maldivian descent. South Asians constitute a significant ethnic and religious minority umbrella group in the United Kingdom - the $2011 \mathrm{~g}$ revealed an estimated population of 4.2 million South Asians in the UK (Office for National Statistics, 2011). There are over 1.4 million British Indians, 1.1 million British Pakistanis and just under half a million British Bangladeshis resident in the United Kingdom.

South Asians are a collectivist society, in which family and community are of cultural importance - for many, these are the important facets of identity and sources of belongingness (Masood, Okazaki \& Takeuchi, 2009). British South Asian identities are complex and multi-layered, and people within this umbrella community identify in a multitude of ways. Some define themselves as 'British Asian' or 'Asian', while others favour more specific ethno-national identities, such as Indian or Pakistani; ethno-regional identities, such as 'Panjabi' or 'Gujarati'; religious identities, such as 'Muslim', 'Hindu' or 'Sikh'; and even caste identities, such as 'Jat' or 'Khatri' (Jaspal, 2011b). Social context often determines the choice of identity and some are intersecting. In short, the category 'British South Asian' is diverse and best described in terms of an umbrella category or as a category of communities, encompassing many significant subgroup identities, albeit with some overlapping cultural characteristics.

One such characteristic shared by British South Asians of all ethnic and religious traditions concerns the importance that they collectively append to the cultural construct of izzat and their shared trepidation about permitting, or engaging in, behaviours that could result in sharam (Ghuman 2003; Werbner, 2005). An essential tenet of maintaining izzat is the fulfillment of the cultural expectation of marriage, which is often arranged, to varying degrees, by the individual's family (Uddin, 2006). Any contravention of cultural norms concerning sexuality, such as coming out as gay, refusing to get married, or marrying someone against one's family's wishes, may be regarded as a threat to izzat and, thus, conducive to sharam (Jaspal \& Siraj, 2011; Samad \& Eade, 2003).

\section{Parental reactions to homosexuality}

Gay men tend to report social psychological difficulties in relation to coming out to their parents - they may experience changes in valued relationships, exposure to discrimination, and negative emotions, such as guilt, shame, and internalised homophobia. In one study (D'Augelli, Grossman \& Starks, 2008), 71\% of the young people perceived their parents' reaction to their coming out to be negative. This may be attributed partly to parents' lack of preparedness for their sons' coming out. Parents may hastily make comments or take action which are construed by their gay sons' as disparaging and denigrating.

Some parents believe that coming out as gay is the result of bad parenting and attribute their child's sexual orientation to an adverse childhood event, which can lead to selfblame. Some elect a strategy of 'loving denial' (see Livingston \& Fourie, 2016), which refers 
to knowledge, but lack of acknowledgement, of their child's sexual identity. This essentially silences the topic without resolving the issues that surround it. This strategy can superficially safeguard the parent-child relationship by downplaying a controversial topic but implicitly signals parental dismay at the child's sexual orientation and their preference to avoid acknowledging it. Such attributional styles and coping strategies can further stigmatise the child's sexual orientation, thereby causing tension in parent-child relations.

Parental acceptance of their child's sexual identity is associated with several positive psychological and interpersonal outcomes in gay men, such as higher self-compassion and lower internalised homophobia (Gertler, 2014). It is important to identify the factors that might facilitate parental acceptance. In their study of 72 gay men, Willoughby, Malik and Lindahl (2006) found that gay men who described their families as cohesive, adaptive and authoritative perceived their parents' reaction to their coming out as less negative than those whose families were disconnected, rigid and authoritarian. These data suggest that a positive family structure is associated with a better coming out experience and, thus, better interpersonal relations in adulthood.

Yet, in collectivist societies, families tend to be hierarchical and, in South Asian communities, patriarchal - they are more likely to be rigid and authoritarian. Not all parents are necessarily aware of, or understand, homosexuality. As Jaspal (2010) has argued, British South Asian parents may hold negative views of homosexuality and have little first-hand contact with gay people. This can make it difficult for them to understand and accept their own child's sexual orientation. They may focus on negative social representations of homosexuality that are associated with their cultural and religious identities (Yip, 2007).

Most British Indians are, at least nominally, of Hindu or Sikh faith (Ghuman, 2003). Neither Hinduism nor Sikhism officially prohibits homosexuality and, thus, homophobia within these communities can more accurately be attributed to 'cultural' rather than theological factors (Jaspal, 2012). Conversely, Islam, which is the religion of most British Pakistanis, generally takes a negative stance on homosexuality and is opposed to Western conceptualisations of homosexuality in the sense of 'coming out' as exclusively gay (Duran, 1993). Yet, in all British South Asian communities, religion is often drawn upon by individuals in order to substantiate their beliefs about homosexuality. Tenets of religion, such as the Story of Lot in the Koran, may be invoked in order to denigrate homosexuality, although there is by no means consensus concerning the interpretation of religious scripture in this regard (e.g. Jamal, 2001).

In his study of twelve parents of British South Asian gay men, Jaspal (2019) found that parents faced psychological distress due to their sons' coming out, and experienced threats to the self-esteem and continuity principles of identity. Self-esteem was challenged due to widespread parental beliefs that their sons were committing a religious sin and that the esteem of their families would be reduced as a result of their sons' coming out. Continuity was jeopardised by parents' belief that they would lose valued relationships with friends, extended family members and ethnic and religious ingroup members as a result of their sons' coming out.

Due to limited social psychological resources for coping with these significant threats to identity, Jaspal's (2019) participants tended to favour denial as a coping strategy. Some apparently denied the reality of their sons' coming out despite having been given this information clearly and unequivocally, while others denied the true implications of this reality. For instance, although the parents participated in the study with the express knowledge that the research objective was to understand their reactions to their sons' coming out, they did not consistently acknowledge their sons' sexual identities during the course of their research project. Some of them continued to construe their sons' sexual orientation as a 'phase' in their sexual identity development and believed that an arranged marriage might 
'rectify' this. This led some of them to continue to plan their sons' marriage and to discuss their plans candidly both with extended family members and with their gay sons.

Those parents who did resign themselves to the reality of their sons' sexual orientation tended to engage in the strategy of isolating themselves (and indeed their close family members) and, thus, avoided interpersonal contact with others. This strategy signalled an element of acceptance, on the one hand, and deflection, on the other hand - parents chose to avoid contact with others to avoid having to acknowledge their sons' sexual orientation and its true implications. Although this strategy enabled them to save face in their respective communities, it could have negative consequences for identity - as members of a collectivist culture, British South Asians lament the loss of relationships with close ethnic and religious community members.

Given that South Asian communities are often concentrated in residential clusters, social and sexual transgressions can become the focus of gossip in close-knit communities and lead to sharam (Werbner, 2005). In some cases, marriage may be regarded and utilised by the family as a means of avoiding potential, or 'rectifying' actual, transgressions of this kind. Marriage may be regarded as a panacea to homosexuality, for instance. Parents and other family members may cynically believe that sexual orientation is socially determined, mutable and, thus, rectifiable through a heterosexual marriage. Understandably, many young British South Asian gay men who are encouraged to get married refuse to do so - they may be unable, or simply unwilling, to enter into a heterosexual marriage. Yet, behaviours that are perceived to jeopardise family honour can trigger processes and outcomes that lead to a forced marriage when the individual in question refuses to comply.

According to the UK Home Office (2012),

[a] forced marriage is a marriage in which one or both spouses do not (or, in the case of some vulnerable adults, cannot) give free and full consent to the marriage and duress is a factor. Duress can include physical, psychological, financial, and emotional pressure, and sexual abuse. This form of marriage is unacceptable within the UK. (p. 3, bold in original)

Some British South Asian parents do regard homosexuality as a serious social transgression which can be 'cured' by an arranged heterosexual marriage (Samad, 2010). The distinction between arranged and forced marriage (Home Office, 2012; Uddin, 2006) can become blurred due to the ambiguous boundaries between persuasion, coercion and force as well as an observed lack of understanding of what 'coercion' actually entails (Renteln, 2004). In British South Asian communities, there may be less acknowledgement of the fact that psychological and emotional pressure also constitutes a form of forced marriage. Some parents deny, or are unaware of, the psychological and emotional pressure that their children experience in discussions about arranged heterosexual marriage. They may have a firm conviction that their actions will actually benefit their children. Samad and Eade (2003) have argued that arranged marriage and forced marriage ought to be viewed as points along a continuum rather than as dichotomous categories.

In essence, British South Asian parents are attempting to protect their identities from threat when they react adversely to their sons' coming out. Many believe that their izzat is at stake and that community members' knowledge of their sons' sexual orientation could bring about sharam. Their actions, though designed to protect identity, may actually result in psychological distress among British South Asian gay men.

\section{British South Asian gay men: identity \& experience}

There is growing research into the identities and experiences of British South Asian gay men, much of which highlights the psychological distress that many face as a result of rejection 
from significant others due to their stigmatised sexual orientation (Jaspal \& Cinnirella, 2010, 2012; Jaspal, Lopes \& Rehman, 2019; Jaspal \& Siraj, 2011; Yip, 2004).

Previous research into British South Asian gay men has focused on their perceptions of coming out (Jaspal \& Siraj, 2011), interpersonal relations on the gay scene (Bassi, 2008) and their response to the cultural expectation of heterosexual marriage (Jaspal, 2014). Much of this work highlights the high risk of identity threat among British South Asians. In one of the first studies of this population, Bhugra (1997) noted feelings of regret, self-deprecation and self-hatred among many of his participants, given the 'traumatic discrepancy' between being Asian and gay. He attributed this traumatic discrepancy to attempts to construct 'a coherent sense of self from the two identities he seeks to attain: Asian and gay' (p. 556), alluding to threats to identity coherence (Jaspal \& Cinnirella, 2010). Homophobia from one's valued ethnic and religious communities can severely undermine the self-esteem principle of identity - individuals may fail to derive a positive self-conception on the basis of their gay identity (Yip, 2007).

British South Asian gay men may perceive their social, cultural and familial environment to be stigmatising towards homosexuality and, thus, unaccommodating of the sexual identity that they construct. They may refrain from coming out as gay. In their interview study of ten British Asian gay men (of Muslim faith), Jaspal and Siraj (2011) found that interviewees experienced shame when contemplating coming out to their parents, siblings and community members because of the stigma surrounding homosexuality. Many believed that, if they did come out to their parents, they would be stereotyped as being 'like White people'.

Some interviewees in their study actually feared physical violence from their family members due to pervasive honour beliefs. Crucially, izzat was a key issue - individuals believed that, by coming out as gay, they would be imperilling their family honour, which in turn could engender adverse consequences for themselves and their family members. Physical violence was just one potential consequence - others included denigration, ostracisation of the family, and adverse effects for the marital prospects of other siblings in the family. These honour beliefs can lead British South Asian gay men to reject the prospect of coming out, which in turn can undermine the self-esteem and coherence principles of identity. They may be unable to derive social support from others, due to their refusal to come out, and resort to denial, self-isolation and other maladaptive deflection strategies for coping with identity threat.

Some differences have been observed in the responses of British Indian and British Pakistani gay men to their sexual orientation (Jaspal, 2012). British Indians, most of whom are of Hindu or Sikh faith, generally report difficulties in disclosing their sexual orientation to other community members due to fear of stigma, rejection and threats to izzat. British Pakistani gay men, most of whom are of the Islamic faith, appear to experience both social and psychological difficulties in that they themselves may believe that their sexual orientation is a sin and that they are, therefore, 'bad Muslims'. For both British Indian and British Pakistani gay men, the family is an important aspect of identity and, given their collectivist cultural orientation, threats to izzat can be challenging at an individual level.

Individuals from British South Asian cultures generally wish to retain a connection with the family and with their respective communities but many believe that coming as out as gay could jeopardise these community connections. Given the importance of the family, British South Asian gay men generally express trepidation about harming the family's izzat and bring about sharam - they are concerned about the adverse impact on the lives of their parents, siblings and other family members. They generally acknowledge the different social structures that underpin the lives of their parents, which tend to be more collectivist and community-oriented than their own. For instance, while British South Asian gay men may 
have access to various social groups and contexts, such as the gay scene, their parents may continue to live within close-knit ethnic and religious communities, which are their primary sources of belongingness. Family honour constitutes a priority for many first-generation British South Asians and second-generation British South Asians are cognisant of the social value appended to izzat.

In their survey study of an ethnically diverse sample of 289 gay, lesbian and bisexual individuals, including those of British South Asian origin, Jaspal, Lopes and Rehman (2019) found that ethnicity was associated with depressive symptomatology, namely depression, psychological distress and suicidality. Moreover, the study showed that this relationship was mediated by situational stressors (i.e. rejection, discrimination, victimisation), psychological self-schemata (i.e. outness, internalised homophobia) and coping variables (i.e. drug use, help-seeking). In short, they found that those individuals who reported higher exposure to situational stressors, a negative psychological self-schema (i.e. internalised homophobia) and maladaptive coping (i.e. drug use) were more likely to manifest psychological distress, depression and suicidality. These data suggest that situational stressors and resultant negative psychological self-schemata predispose gay men (and indeed other sexual minorities) to depressive symptomatology. British South Asian gay men do appear to face situational stressors and to develop negative self-schemata due to coercive honour beliefs, which, in the absence of social support, can result in maladaptive coping strategies. These strategies can include denial, fantasy, isolation and, as Jaspal, Lopes and Rehman's (2019) study suggests, drug use.

As indicated earlier in this chapter, an arranged heterosexual marriage may be regarded as a means of changing one's sexual orientation. Understandably, this perception can have a significant impact on identity processes among British South Asian gay men whose parents and family members pressure them into a heterosexual marriage. In another study, Jaspal (2014) asked twelve British South Asian gay men to keep a personal diary to document their relationship with their parents amid parental pressure to get married. Study participants consensually described various forms of psychological and emotional coercion from their parents, such as repeatedly having to consider marital proposals, being asked to provide a reason for rejecting proposals, and enduring the guilt of letting their parents down. Despite having disclosed their sexual orientation to their parents, some individuals reported parental dismissal of this information and denial of its implications - their parents clearly believed that a heterosexual marriage would succeed in changing their sons' sexual orientation.

Parental pressure to get married appeared to cause identity threat - especially in relation to the self-esteem and continuity principles of identity - and significant psychological distress. In their diaries, individuals described feelings of anxiety, shame, and guilt in relation to their sexual orientation and believed that they were bringing shame on their families. In response to such identity threat, British South Asian gay men may attempt to cope by engaging in various deflection strategies. Some study participants engaged in the strategy of fantasy and denied their current reality by 'escaping' psychologically to their childhood so that they did not have to contemplate marriage. Others disengaged from family members, avoiding first-hand contact with them, in order to evade the topic of marriage and the threats to identity that consideration of this topic entailed.

Yet, a sizeable number of British South Asian gay men did come to view marriage in terms of a dilemma - on the one hand, they accepted their sexual orientation and, thus, did not wish to enter into a heterosexual marriage but, on the other hand, they themselves believed that a heterosexual marriage is more consistent with the norms, values and expectations associated with their ethno-religious identities. In such cases, individuals believe that a heterosexual marriage could simplify their lives, from an ethno-religious perspective at 
least. They too may come to view marriage as a panacea and as a means of safeguarding izzat. In conjunction with deflection strategies, such as fantasy and denial, contemplating an arranged marriage can easily become a reality - often with unfavourable consequences for identity among all involved.

\section{Conclusions}

Honour beliefs are pervasive in British South Asian communities. These beliefs are grounded in long-standing social representations that are associated with ethno-religious identities.

They can therefore be coercive and inescapable for both British South Asian gay men and for their parents if they wish to forge a sense of belonging in their ethno-religious communities. Yet, these beliefs can cause considerable psychological distress to British South Asian gay men struggling to assimilate and accommodate their sexual orientation in their identity and lead them to evaluate their emerging sexual identities negatively. This itself is associated with the onset of internalised homophobia, which can have insidious social psychological consequences, such as poor mental health and sexual health outcomes.

It is noteworthy that honour beliefs can also cause identity threat among the parents of British South Asian gay men struggling to understand and accept their sons' sexual identity, which may be perceived as being at odds with family honour. Parents may come to engage in irrational behaviours designed to protect family honour and, by extension, their identities. This can include honour abuse against their gay children. When viewed through the lens of identity process theory, behaviours that are described as 'honour abuse' may actually constitute maladaptive coping strategies. British South Asian gay men's uncritical acceptance of these behaviours, such as acquiescing to an arranged heterosexual marriage, may also be a maladaptive coping strategy. These strategies may have short-term benefits for honour and identity but are unlikely to be successful in the long term, causing secondary threats to identity, further patterns of maladaptive coping and psychological distress.

On the basis of this chapter, at least three practical recommendations can be made to support those at risk of identity threat due to honour beliefs:

- First, there is a need for greater awareness and understanding of sexual orientation in British South Asian communities. The widespread social representation of homosexuality as a 'chosen' and, thus, mutable state must be challenged. Social representations of honour (izzat) and shame (sharam) must also be challenged within British South Asians communities. Clearly, community leaders will need to take a proactive stance on challenging long-standing honour beliefs, understandings and practices. Similarly, young British South Asians ought to be informed about diversity in a positive and proactive way - ideally within the context of sexuality education programmes in schools - so that future generations are more accepting and accommodating of both their own and others' (sexual) identities.

- Second, British South Asian parents appear to have few sources of social and psychological support in relation to their children's coming out. In view of pervasive honour beliefs, this can be a psychologically aversive experience and coping is difficult. The availability of culturally competent support networks and psychological support services would facilitate effective coping and potentially reduce the risk of engagement in maladaptive strategies, such as honour abuse. An evidence-based selfhelp guide for British South Asian parents would be a very useful resource.

- Third, although the Home Office (2012) does acknowledge non-violent forms of coercion, in practice there must be greater social, legal and institutional acknowledgement of subtler forms of forced marriage, which involve psychological and emotional coercion in the ways described by British South Asian gay men themselves (e.g. Jaspal, 2014). The boundaries between arranged marriage and forced 
marriage can easily become blurred - with distressing consequences for British South

Asian gay men. Honour beliefs are clearly a causal factor.

Using social representations theory and identity process theory, it has been shown that honour beliefs can shape, protect and challenge identity processes among both British South Asian gay men and their parents. These theories will undoubtedly help to inform interventions to challenge honour beliefs that curtail identity development and psychological wellbeing among British South Asian gay men. These interventions must focus on re-configuring negative social representations of homosexuality, facilitating a positive sexual identity among British South Asian gay men, and supporting the parents of British South Asian gay men struggling to reconcile homosexuality and honour.

\section{REFERENCES}

Bassi, C. (2008). The precarious and contradictory moments of existence for an emergent British Asian gay culture. In C. Dwyer \& C. Bressey (eds.), New geographies of race and racism (pp.209-22). Farnham, UK: Ashgate.

Bhugra, D. (1997). Coming out by South Asian gay men in the United Kingdom. Archives of Sexual Behaviour, 26, 547-57.

Breakwell, G.M. (1986). Coping with threatened identities. London: Methuen.

D'Augelli, A. R., Grossman, A. H., \& Starks, M. T. (2008). Families of gay, lesbian, and bisexual youth: What do parents and siblings know and how do they react? Journal of GLBT Family Studies, 4(1), 95-115.

Duran, K. (1993). Homosexuality in Islam. In A. Swidler (Ed.), Homosexuality and world religions (pp.181-198). Harrisburg, PA: Trinity Press.

Gertler, L.M. (2014). The coming out experience, internalized homophobia and selfcompassion in LGBQ young adults. Unpublished PsycD thesis, The Wright Institute, Berkeley, USA.

Ghuman, P.A.S. (2003). Double loyalties: South Asian adolescents in the West. Cardiff: University of Wales Press.

Gill, A. (2011). Reconfiguring 'honour'-based violence as a form of gendered violence. In M.M. Idriss \& T. Abbas (eds.), Honour, Violence, Women and Islam (pp. 218-231). Oxford: Routledge.

Gill, A. \& Brah, A. (2014). Interrogating cultural narratives about 'honour'-based violence'. European Journal of Women's Studies, 21(1), 72-86.

Home Office (2012). The right to choose: Guidance and instruction on forced marriage. Available at https://www.basw.co.uk/system/files/resources/basw_93347-2_0.pdf Accessed on 3 August 2019.

Jamal, A. (2001). The story of Lot and the Qu'ran's perception of the morality of same-sex sexuality. Journal of Homosexuality, 41(1), 1-88.

Jaspal, R. (2010). Identity threat among British Muslim gay men. The Psychologist, 23(8), 640-41.

Jaspal, R. (2011a). Caste, social stigma and identity processes. Psychology and Developing Societies, 23(2) 27-62.

Jaspal, R. (2011b). Delineating ethnic and religious identities in research with British South Asians. Psychological Studies, 56(2), 214-244

Jaspal, R. (2012). "I never faced up to being gay": Sexual, religious and ethnic identities among British South Asian gay men. Culture, Health and Sexuality: An International Journal for Research, Intervention and Care, 14(7), 767-80.

Jaspal, R. (2014). Arranged marriage, identity and psychological wellbeing among British Asian gay men. Journal of GLBT Family Studies, 10(5), 425-448. 
Jaspal, R. (2019). Parental reactions to British South Asian young men who come out as gay. Journal of GLBT Family Studies. https://dx.doi.org/10.1080/1550428X.2019.1684412 Jaspal, R. \& Breakwell, G.M. (eds.) (2014). Identity Process Theory: Identity, Social Action and Social Change. Cambridge: Cambridge University Press.

Jaspal, R. \& Cinnirella, M. (2010). Coping with potentially incompatible identities: accounts of religious, ethnic and sexual identities from British Pakistani men who identify as Muslim and gay. British Journal of Social Psychology, 49(4), 849-870.

Jaspal, R. \& Cinnirella, M. (2012). Identity processes, threat and interpersonal relations: accounts from British Muslim gay men. Journal of Homosexuality, 59(2), 215-40.

Jaspal, R. Lopes, B. \& Rehman, Z. (2019). Depressive psychopathology in Black \& Minority Ethnic lesbian, gay and bisexual people in the UK. Paper presented at the 33rd Annual Conference of the European Health Society, Dubrovnik, Croatia, 4-7 September 2019. Jaspal, R., Nerlich, B. \& Cinnirella, M. (2014). Human responses to climate change: social representation, identity and socio-psychological action. Environmental Communication: A Journal of Nature and Culture, 8(1), 110-130.

Jaspal, R. \& Siraj, A. (2011). Perceptions of 'coming out' among British Muslim gay men. Psychology and Sexuality, 2(3),183-197.

Livingston, J. \& Fourie, E. (2016). The experiences and meanings that shape heterosexual fathers' relationships with their gay sons in South Africa. Journal of Homosexuality, 63(12), 1630-1659.

Masood, N., Okazaki, S., \& Takeuchi, D. T. (2009). Gender, family, and community correlates of mental health in South Asian Americans. Cultural Diversity and Ethnic Minority Psychology, 15(3), 265-274.

Moscovici, S. (1988). Notes towards a description of social representations. European Journal of Social Psychology, 18, 211-250.

Office for National Statistics (2011). 2011 Census.

https://www.ons.gov.uk/census/2011census Accessed on 2 August 2019.

Renteln, A.D. (2004). The cultural defense. Oxford: Oxford University Press.

Samad, Y. (2010). Forced marriage among men: An unrecognized problem. Critical Social Policy, 30, 189-207.

Samad, Y. \& Eade, J. (2003) Community Perceptions of Forced Marriage. London: Foreign and Commonwealth Office.

Soni, S. (2013). 'Izzat' and the shaping of the lives of young Asians in Britain in the 21st century. Unpublished PhD dissertation, University of Birmingham, UK.

Uddin, M.S. (2006). Arranged marriage: a dilemma for young British Asians. Diversity in Health and Social Care, 3, 211-19.

Vandello, J.A. \& Cohen, D. (2003). Male honor and female fidelity: implicit cultural scripts that perpetuate domestic violence. Journal of Personality and Social Psychology, 84(5) 9971010.

Werbner, P. (2005). Honor, shame and the politics of sexual embodiment among South Asian Muslims in Britain and beyond: An analysis of debates in the public sphere. HAGAR International Social Science Review, 265(1), 25-47.

Willoughby, B.L.B., Malik, N.M. \& Lindahl, K.M. (2006). Parental reactions to their sons' sexual orientation disclosures: The roles of family cohesion, adaptability, and parenting style. Psychology of Men \& Masculinity, 7(1), 14-26.

Yip, A.K.T. (2004). Negotiating space with family and kin in identity construction: The narratives of British non-heterosexual Muslims. Sociological Review, 52, 336-350.

Yip, A.K.T. (2007). Sexual orientation discrimination in religious communities. In M.V.L. Badgett \& J. Frank (eds.), Sexual Orientation Discrimination: An International Perspective (pp. 209-244). London: Routledge. 
Yip, A. K. T. \& Khalid, A. (2010). Looking for Allah: Spiritual Quests of Queer Muslims. In K. Browne, S. Munt \& A.K.T. Yip (eds.) Queer Spiritual Spaces (pp. 81-110). London, , UK: Ashgate. 